\title{
Factors Influencing Customer Engagement in Social Commerce Websites: A Systematic Literature Review
}

\section{Abdelsalam H Busalim¹, Ab Razak Che Hussin² and Noorminshah A. lahad ${ }^{3}$}

Universiti Teknologi Malaysia, Department of Information Systems, Johor Bahru, Malaysia

${ }^{1}$ hbabdelsalam@live.utm.my, ${ }^{2}$ abrazak@utm.my, ${ }^{3}$ minshah@utm.my

Received 10 October 2017; received in revised form 12 March 2018; accepted 29 April 2018

\section{Abstract}

The evolution of social commerce (s-commerce) has changed both businesses and customers. Therefore, understanding customer engagement behaviour in the s-commerce context has become a key competitive advantage for companies that aim to build a customer-centric business. The purpose of this study is to provide an in-depth review of customer engagement studies in the context of s-commerce. This study used a systematic literature review approach on customer engagement studies in the context of s-commerce. The results show that social theories and factors play a significant role in customer engagement along with technological factors. More importantly, drawn from the review results, a research framework was developed to show the factors that provide the greatest influence in customer engagement behavior.

Keywords: Customer engagement, Social commerce, Social media, Systematic literature review, Research Framework 


\section{Introduction}

The field of s-commerce has emerged as a new form of e-commerce involving the use of social media that supports social interactions and user contributions to assist activities in the buying and selling of products and services [91]. The emergence of s-commerce transformed the role of customers into active transaction players by empowering them to participate in the marketing, selling, comparing, curating and buying in online marketplaces [33]. Therefore, understanding customer behaviour in the context of s-commerce has become critical for companies that seek better customer role interaction and aim to utilise the power of social media [65], [100].To harness the impact of scommerce, there is a need to understand how brands can leverage social media platforms such as Facebook and Twitter to engage and collaborate with customers [20], [105].

The concept of customer engagement (CE) emerged in 2006 as a sub-set of the term engagement that sought to study the customer's behavior and emotions toward the interactions/participation with brands/services [85]. Recently, CE has become one of the Marketing Science Institute's (MSI) research priorities between 2014 and 2016 [40]. Customers can generate value to companies through ways other than purchasing [50]. Non-transactional customer behavior has become a key concept in recent years [83].Therefore, finding alternative methods by which to build relationships, engage customers and create communities by utilising the growth of social media provide a competitive advantage to e-commerce companies [34]. However, engaging customers consistently and correctly is a continuing challenge for companies that sell online [5]. In the s-commerce context, most research studies focus on the influence of s-commerce on business outcomes and few investigations were done to explore users' attitudes and behaviors as related to s-commerce engagement [28]. Previous stduies clearly highlighted that there is a lack of identifying the factors that affect CE in s-commerce [18], [72]. Therefore, these gaps showed that a proper systematic literature review (SLR) to address the theories/factors influencing customer engagement behaviour (CEB) in the s-commerce is needed. Moreover, CE research gave only scant attention to the social dimensions involved in relationship marketing and online shopping [53]. To this end, the purpose of this study is to conduct SLR on CEB in s-commerce. First, we address the conceptualization of CE and then highlight the theories/factors adopted in prior studies to expose the theoretical foundation in this setting. Then, we develop a research framework to illustrate the relationship between the adopted factors to understand CEB in the s-commerce context better. We believe that this framework provides a useful foundation for future s-commerce research.

This paper is organised as follows: The next section discusses s-commerce definitions and scope. Second, we illustrate the review method of studies on CE in s-commerce. Third, we report on the SLR results and conduct a detailed discussion of the development of the research $\mathrm{h}$ framework. Fourth, we discuss the implications of the SLR. Finally, we conclude the SLR and discuss opportunities for future work.

\section{Social Commerce}

Prior research has broadly classified s-commerce into two main elements: social activities and commercial activities [53], [99]. Looking at s-commerce definitions in the literature reveals that it still does not have a standard definition and is associated with some inconsistencies. For example, in [77], the authors defined s-commerce as "the use of Internet-based media to enable users to participate in the selling, buying, comparing, and sharing of information about products and services in online marketplaces and communities". In [72], the authors defined s-commerce as an evolution of Web 2.0 of online commerce, allowing greater interactivity and participation of and among customers using blogs, wiki systems and sharing of articles written by its own community members. On the other hand, scommerce is considered to be a subset of traditional e-commerce that involves using Social Networking Sites (SNSs) to support social interaction for the online buying and selling of products and services [58], [99] . In contrast, in [61], s-commerce has been defined as selling via social media websites, such as Facebook. However, this conceptual diversity in s-commerce definitions brought a different understanding of what s-commerce means. Recent studies have identified two major types of s-commerce, namely: (1) social network sites that integrate commercial features so as to allow transactions and advertisements for users; and (2) the traditional e-commerce websites, such as Amazon and eBay that add social networking tools to facilitate social interaction among customers [63], [99]. We note that the majority of the previous studies focus on the first type of s-commerce (i.e., [2], [69] ). On the other hand, Amblee and Bui [2] considered Amazon as a practical form of s-commerce because it contains social interactions in the form of online reviews. Group buying websites such as Groupon.com are also considered to be a form of scommerce, where people form a group to purchase products with discount advantages [44]-[45], [88]. While a variety of definitions have been suggested, this study will rely on definitions that serve the goal of this study. Therefore scommerce defined in this study as "a subset of e-commerce that uses social media, that support social interaction and users contributions, to enhance the online purchase experience, by allowing them to engage in a collaborative online environment" [19]. 


\section{Methodology}

Following the guideline provided by Bandara et al. [6], this study employed a four-phase method to extract, codify, analyse, and interpret the existing CE studies. This includes the phase of articles extraction, Pre-analysis, Actual coding and Write-up the results. The following sub-sections provide a detailed explanation of each stage. The aim of the study is to answer the following questions:

1. What are the conceptualizations of CE?

2. What are theories adopted in the previous CE studies?

3. What are the important factors studied to understand CE in the context of s-commerce?

\subsection{Identification and Extraction of Studies}

In the first phase, we first identify and select the primary studies from several online databases that are used to cover a wide range of publications. Based on recommendations in [95], we did not limit the search process to a specific set of journals. The duration of selected studies extends from 2010 to 2017. The reason for choosing this period is to complement previous efforts [71], [91] to provide a deep understanding of s-commerce. The databases used were ScienceDirect, Scopus, Springer, IEEE Explorer, ACM Digital Library, AIS e-Library. These databases are relevant and provide reliable studies. The studies were extracted using keywords related to the research questions of this review, namely: customer engagement, consumer engagement/participation as well as s-commerce engagement and social e-commerce. In every database, we have used each keyword separately or combined with other keywords, using the advanced search tool provided by online databases, this search process is to ensure the accuracy and reliability of the results. A total of 246 studies related to CE in s-commerce were identified. After removing the duplicated studies using the Mendeley software, a total of 240 studies remained. Afterwards, we applied inclusion/exclusion criteria for the title, abstract and conclusion. Table 1 shows the inclusion and exclusion criteria were used in this study.

Table 1: Inclusion and exclusion criteria

\begin{tabular}{|l|l|}
\hline Inclusion Criteria & Exclusion Criteria \\
\hline Full-text & Uncompleted studies \\
Published within selected period (2010-2017) & Non English \\
Published in the above-selected database & Outside the selected time \\
Study manuscript was written in English. & Conceptual or non-empirical \\
In the domain of customer engagement/ s- & studies \\
commerce & \\
\hline
\end{tabular}

After applying the inclusion and exclusion criteria, a total of (108) studies remained after applying full-text scanning to each paper.The distribution of the studies through the years is shown in Figure 1. As can be seen the graph, the publication of customer engagement in s-commerce context have gradually increased from 2010 to 2014 . The highest number of publication was recorded in 2014 with 30 studies. In 2015 and 2016 the number of studies published were 22 and 12 respectively. In 2017, only 9 studies were published. This distribution shows how the interest of customer behavior in e-commerce has increased by years.

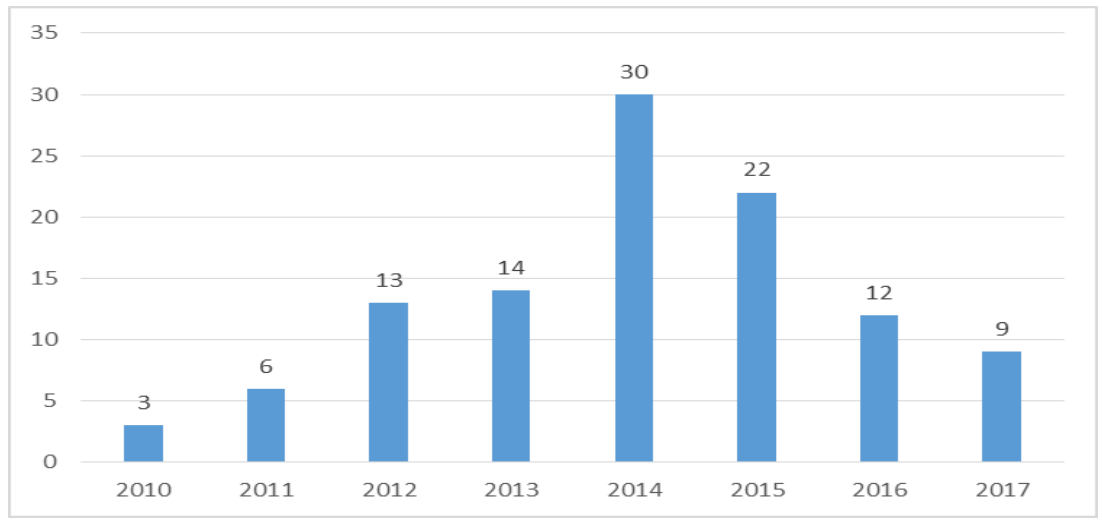

Figure 1: Publication timeline 


\subsection{Preparing for Analysis}

The pre-analysis phase includes all the activities required for the analysis. First, building references database for all the primary studies using Mendeley, then exporting all the primary studies as pdf files to Nvivo 10 software. Second, developing Pre-coding scheme to be used as main nodes in Nvivo 10. The pre-coding nodes were suggested; CE definitions, CE factors, and CE theories and models (Figure 2). These nodes answer the SLR questions. The precoding scheme aims to capture all the content that relates to each main theme of the coding scheme within the specific node.

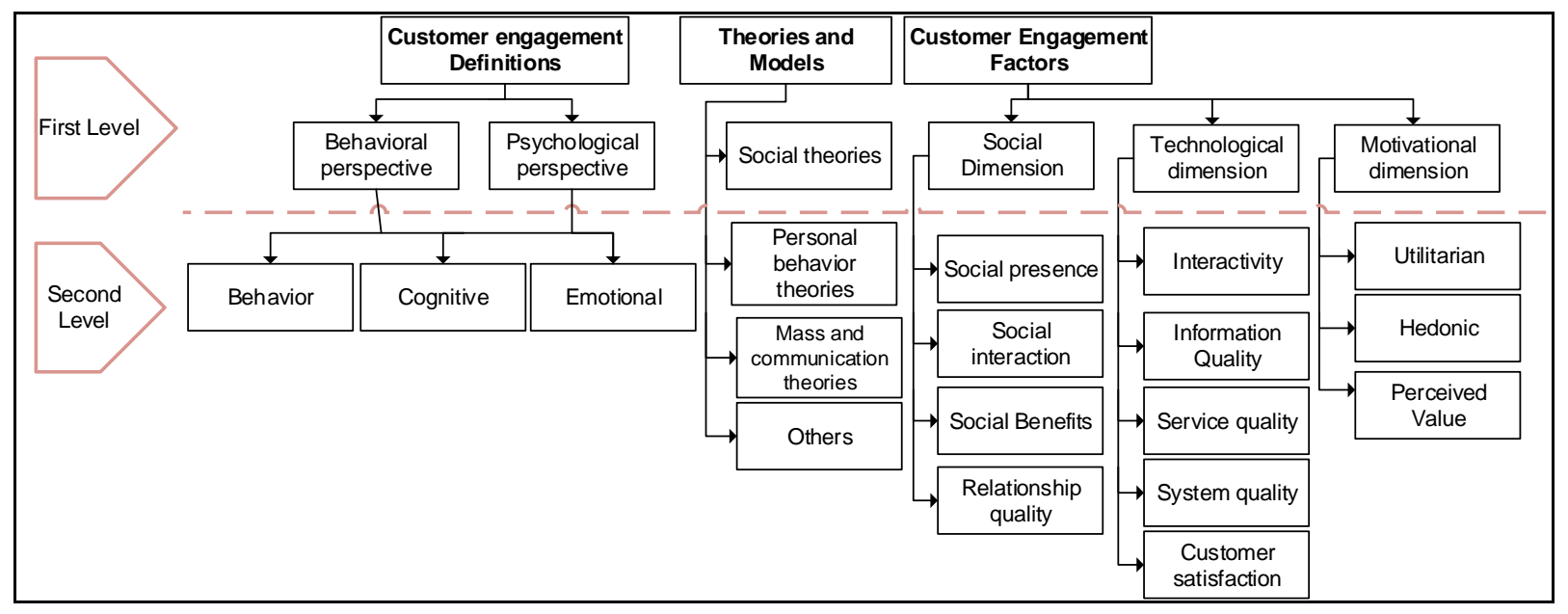

Figure 2: Coding levels

\subsection{Actual Coding and Write-Up}

This phase covers the coding process in which we screen the full-text of each study and capture all of the relevant text related to each of the suggested four nodes; this stage is called the first level of coding. The coded text under each node is then analysed, and another sub-node is developed based on the text analysis. In the second level of coding, we reviewed in-depth the sub-nodes and deductively derive another sub-level of each node as shown in figure 2. To ensure the accuracy and coding reliability, we developed a coding protocol as recommended by Bandara et al. [6]. At the first level of analysis, the actual coding of the information related to each node was coded by the first coder, then the second coder (Master coder) reviewed all the coded information of the first level coded by the first coder and made sure that the information was very relevant to each node. If not sufficiently relevant, the master coder had to recode the information. The same process was carried on the second level of analysis. When the first coder created the sub-node of each main node, the master coder must extensively review the information of each sub-node to ensure the relevance of this information to a particular node. The coding process is shown in Figure 3. The final phase involves synthesising the coded text under the nodes and writing the findings. We derived a descriptive overview of the SLR results, namely, a summary of the published sources and reported the results of the SLR questions.

\section{Results}

This section provides a detail answers of the SLR questions for this review. First, we discuss how previous studies conceptualized and defined the term Customer engagement, second, we present the theories and models that have been used in previous studies, and final section provides discussion on the factors that inflaunce CE in s-commerce context.

\subsection{Conceptualising Customer Engagement}

Building on different theoretical backgrounds, CE was defined by various researchers in different disciplines. Despite the increasing interest in CE research, the concept remains in the early stages of research [40]. The emergence of social media applications that build on the foundation of Web 2.0 forms an important development in the customercompany relationship and allows the creation and exchange of user-generated content [15], [97]. In studies published to date, CE is defined in terms of a combination of cognitive aspects (e.g. being interested in a company's activities); behavioral aspects (participation in the company's activities); and emotional aspects (feeling positive about a company's activities). In [86], CE refers to the level of a customer's cognitive, behavioral and emotional existence in an online brand community. Based on the reviewed articles, we have summarized that there are two 
main perspectives from which researchers have defined and studied the concept of CE in prior literature: the psychological perspective and the behavioral perspective.

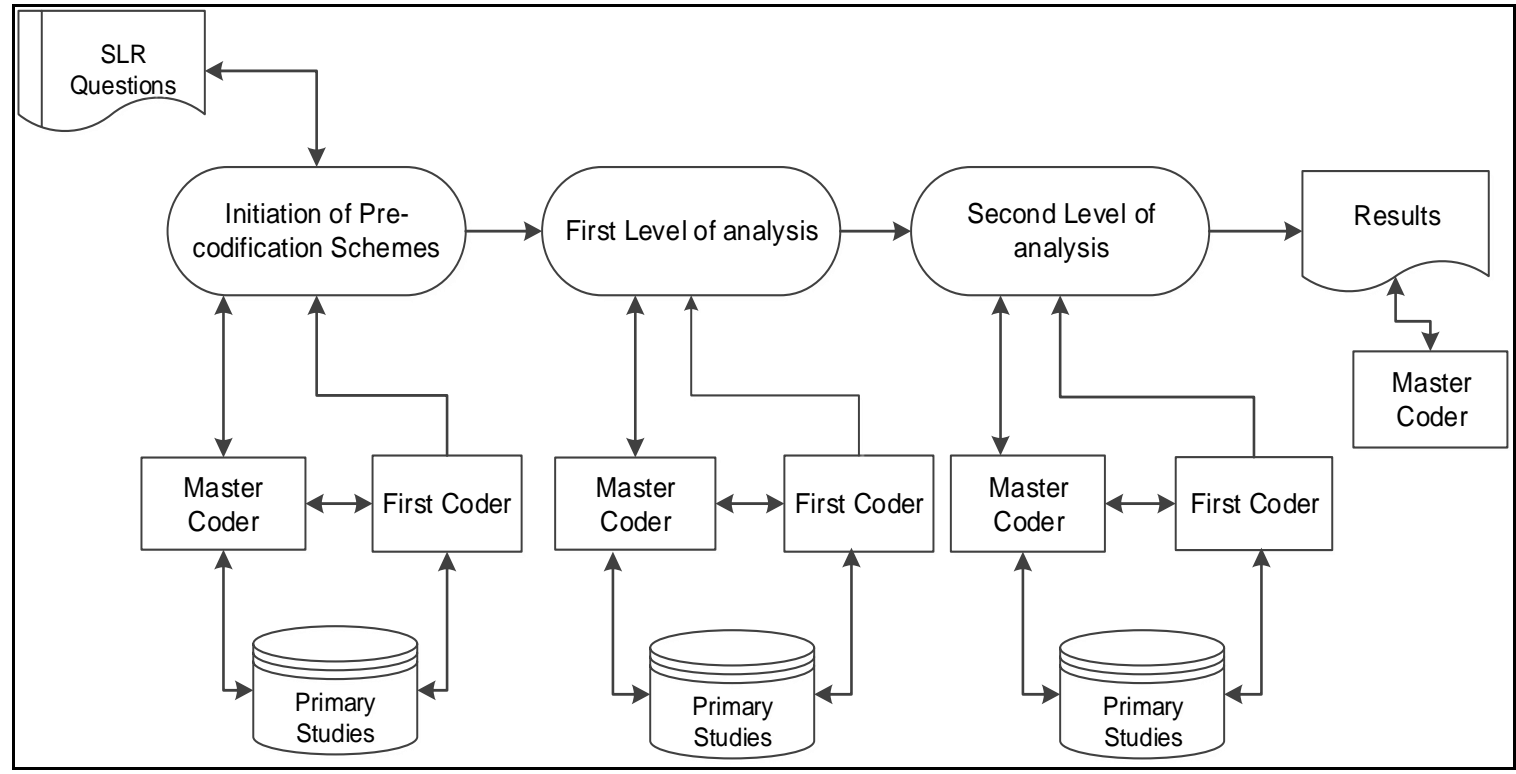

Figure 3: Coding protocol

\subsubsection{Behavioral Perspective}

According to our review, most of the studies focus on CE as a behavioural aspect that considers all nontransactional behaviours that can affect a firm [8], [83] and is defined as customer's behavioural manifestations that have a brand or firm focus, beyond purchase, resulting from motivational drivers [78]. Other researchers also defined CE as behavioral manifestations and provided a number of related behaviours, such as word-of-mouth, blogging and ratings, [14], [15], [83]. Companies increasingly look at the non-transactional activities as a route for building and sustaining the customer relationship. Advocacy, as a result of non-transactional behaviour, is one of the most important outcomes of CE and helps a company to extend their promotional budget [39]. In information systems research, CE comprises both user participation and involvement [88], and it is defined as the intensity level of a customer to participate together with the company and with other customers in a cooperative knowledge exchange and information-sharing process [87], [102]. However, Participation is commonly used to describe this behavioural dimension of CE [14]. Because s-commerce involves two main attributes (social activities and commercial activities), CEB in s-commerce environment contains both transactional and non-transactional behaviour. The direct transaction indicates the purchasing behaviour of a customer during the buying process. Similarly, non-transactions refer to referral, information-sharing activities, information seeking, and after-sales phases of the customer [13]. However, this study focus on CE as Behavioural aspect, and used the well-known definition by van Doorn et al. [78] who defined CEB as customer's behavioral manifestations that have a brand or firm focus beyond purchase, resulting from motivational drivers.

\subsubsection{Psychological Perspective}

In this perspective, CE is defined as a psychological state that occurs as a result of using an interactive platform. It can also come about as a customer co-creation experience with a central object or agent, for example, a brand or product, in central service relationships. It occurs under a specific set of context conditions that generate various levels of CE. It was suggested that the roots of the CE concept might be exposed by drawing on a theory addressing the indicative experience of customers and value co-creation [79]. This perspective has been formed as 'service dominant (SD) logic [59], [80]. The service-dominant logic is a theoretical lens that recognises that customer behaviour outcomes are generated by customers' particular interactive value co-created experiences with particular brands. Similarly, some research refers to CE as co-creative and interactive consumer experiences with the focal agent/object that leads to a particular psychological state [62], [79]. In addition, the characteristics of the psychological state in CE is determined by the degree of vigor, dedication, interaction and absorption in brand activities and community interaction [11]. On the other hand, some studies see CE as a psychological process that leads to the creation of customer loyalty [36]. This comprises both a cognitive aspect and an emotional aspect to define CE as a psychological process. In the same context, Hollebeek [36] defined customer brand engagement as 'the level of a customer's motivational, brand- related and context-dependent state of mind characterised by specific levels of cognitive, emotional and behavioral activity in brand interactions. Figure 4 summarises the main CE prespactives. 


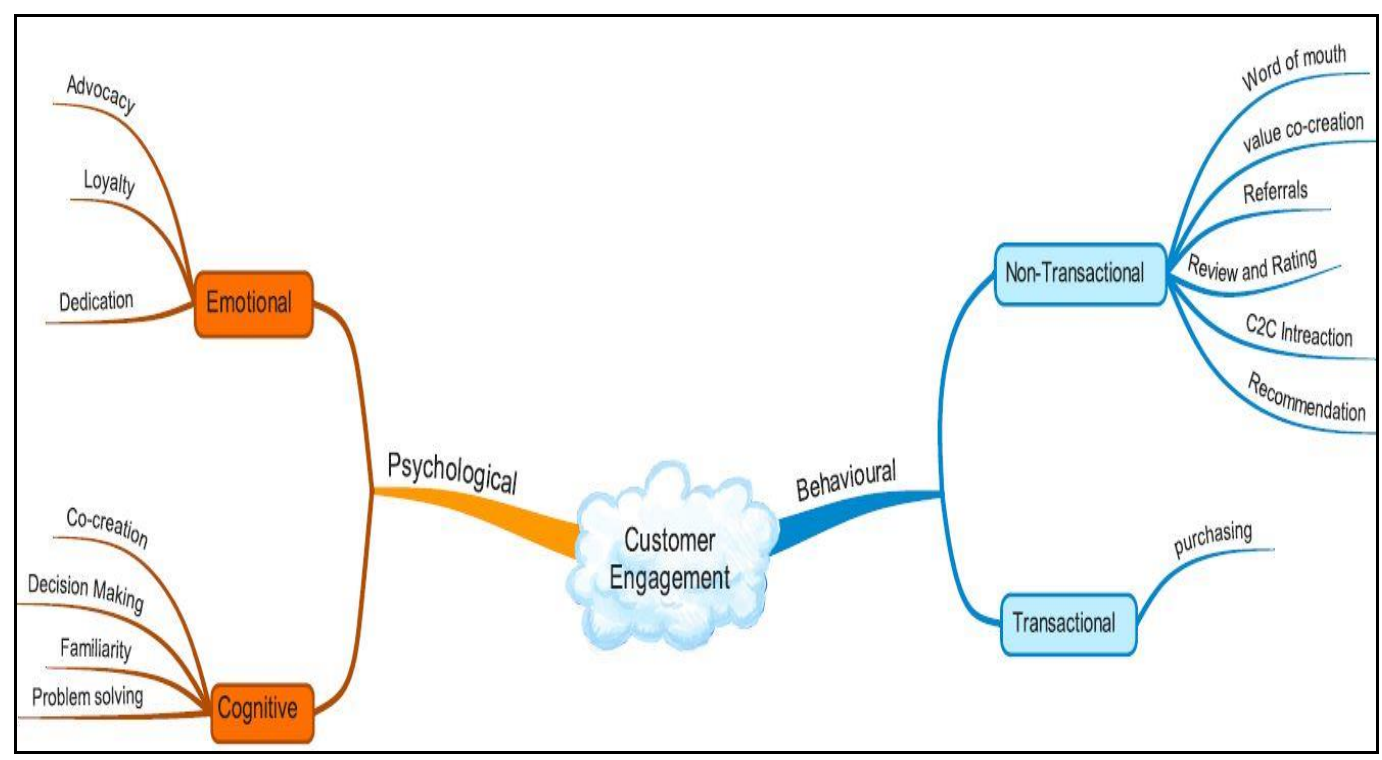

Figure 4: Mind map of customer engagement prespactives

\subsection{Theories and Models}

This section underlines the theories and models used in the extant literature regarding CE in s-commerce to study the socio-psychological behavior of customers. Table 2 shows that the uses and gratification theory, social support theory and information success model have mostly been adopted in previous studies. Upon further analysis, we dug deeper into the data and classified the theories as related social theories (Social support, social presence, social exchange, and social influence); mass communication (e.g., Uses and gratification, Parasocial interaction); and behavioral theories, such as (Theory of planned behavior and Theory of reasoned action). A detailed theoretical discussion was emphasised in addressing the CE in s-commerce. We highlighted some of these emphases on the most essential and significant theories/model as discussed below

Table 2: Well-utilised Theories and models

\begin{tabular}{|l|l|}
\hline Theory/Model & References \\
\hline Uses and Gratifications Theory & {$[1],[7],[38],[41],[97]$} \\
\hline Information systems success model & {$[46],[94],[103]$} \\
\hline Stimuli-Organisms-Responses & {$[102],[103]$} \\
\hline Social support & {$[31],[33],[75]$} \\
\hline Motivation theory & {$[81]$} \\
\hline Resource exchange theory & {$[21]$} \\
\hline Social presence & {$[21],[47],[74]$} \\
\hline Social exchange & {$[21],[84]$} \\
\hline ECM Model & {$[42]$} \\
\hline Theory of Planned Behaviour & {$[9],[33]$} \\
\hline Theory of Reasoned action & {$[72]$} \\
\hline Parasocial Interaction & {$[63]$} \\
\hline
\end{tabular}

Uses and gratification theory (UGT) was developed by Katz et al., [43]. It is one of the mass communications and has been widely employed to investigate the wide range of traditional media such as television, newspapers, radio and telephones [97]. UGT is described as "The social and psychological origins of needs which generate expectations of mass media and other sources which lead to differential patterns of media exposure (or engagement in other activities) resulting in needs gratifications and other consequences" [82]. Since the growth of internet usage, the interest in applying UGT in various domains has continued to flourish [54]. Nowadays, there is a growing stream of research using UGT for the emerging internet-based platforms and applications that are used to foster interaction and communication among people, such as: social media, virtual communities, and instant massaging blogs [54]. UGT provides a nomological concpet for research, it does not have a predefined set of constructs [67]. The main objective of UGT is to attempt to understand the psychological needs of people which encourage them to use media and the reasons that motivate them to engage in certain types of media [56]. UGT has three basic assumptions [97]. First, people are active in seeking the type of media that can be used to satisfy their needs. Second, people intentionally select media to fulfill their communication purposes, and their behaviors are goal-oriented. Finally, they know their motives behind selecting a specific type of medium. One of the strengths of UGT and its classification of benefits lies in the flexibility of study of various behavioral patterns across different media usage contexts [54]. 
Recentlt, UGT has received attention in s-commerce and social shopping research in investigating what motivates customers to engage in s-commerce platforms/fan pages; and also how to satisfy customers' needs as mentioned in the studies by [46], [47], [72], [97]. In [41], the authors have examined three categories of gratifications that customers are seeking for when they are engagaing in brand fan pages. The results show that hedonic value, functional value, brand intreaction value and self-concept value are positivly influence on fan page uasge intensitty, and fan page engagament. Moreover, a recent study by Hur, [38] emphsized that, UGT is an appropriate framework to investigate intreactive media and social media related issues.

The important role of social aspect brought by the social nature of s-commerce allows the researchers to derive theoretical insights into s-commerce from social-related theories [99]. As presented in Table 2, Social Support Theory (SST) is widely used, it is defined as a dynamic process that involves interaction between providers and recipient and varies by recipient and provider [52]. SST indicates that when social support exists in a social network, it would be natural for community members to share commercial information and recommendations as an extension of their sharing of other supportive information [32]. However, social support (e.g. information support and emotional support) fulfils customers' social needs and inspires them to conduct useful interaction between each other. Zhang et al., [102] highlighted that the characteristics of s-commerce are bases on content and social relationship. Thus, scommerce involve informational support and emotional support [31], [52] . Emotional support includes being able to rely on another person to contribute on the feeling that one is loved or cared about member of the group [30]. Informational support refers to providing information and advice that could help another person. This information can be in various forms such as, recommendations, advice, and knowledge. In s-commerce research, social support role has been posited as, when there is a sense of social support in the website, customers will naturally share infomartion and recommend products and services with other members of the website as an extension of their sharing of supportive information [32]. However, social support fulfill customers' social needs and inspire them to engage in useful interaction between each other's. The interactions and supportive information increase, customers enter into more satisfying and warm relationships. With the emergence of Web 2.0 and social relationships in social technologies, social support become key factor in business studies [27], [33]. The main reason why people join online communities is for social support and to exchange relevant information [5]. Individuals use social technologies, such as social media, online communities and other Web 2.0 applications to support other members through their experiences and information sharing [27]. For example, Twitter members regularly provide social support for others [31].

The SLR results show that the factors, such as website quality and technological features in s-commerce have gained considerable attention among researchers. Research shows that the level of CE on s-commerce is influenced by the quality (e.g. service quality and information quality) of particular websites [46]. Prior studies adopted the DeLone \& McLean [22]-[24] success model to reveal insights on s-commerce platforms. The D\&L model suggests that e-commerce success can be determined by six dimensions, specifically: system quality, information quality, user satisfaction, system use, individual impact, and organisational impact, respectively. The model suggests that customers' attitude depends on their belief about the quality of the e-commerce systems. The D\&L model was used to examine the internet shopping site qualities on hedonic and utilitarian values, in addition to their influence on repurchase intention [46]. Another attempt to use the D\&L model was by W.-T. Wang et al [94] to study the stickiness of users in business to customer group buying sites.

\subsection{Factors Influence Customer Engagement in S-Commerce}

Through the SLR, we are further able to identify and cluster a number of key factors influence CEB in s-commerce and provide a comprehensive picture of the roles played by these factors. Figure 5 shows the reserach framework to express the inter-relationship of different research dimensions and the factors that influenc CEB. In brief, the framework as showen in figure 5, consists antecedents, moderators, and outcomes. The antecedents are the factors that have an influence on CE and lead to outcomes, whereas the moderators explain the causalities between the antecedents and outcomes.

\subsubsection{Social Factors}

The social support concept is derived from social support theory [51], [73], which was introduced to explain how social relationships influence cognition, emotion and behaviors [26], [93]. Based on our analysis, a number of studies have used social support as an antecedent to examine the customer's continued use, participation in and engagement with the s-commerce context. N. Hajli et al. [33] adopted the theory of planned behavior to study continuance participation in s-commerce online communities. In addition, they emphasised that considering a social support construct contributes to the positive engagement of users in their online community. Moreover, Y. Wang et al [93] used social support to examine the role of s-commerce in co-creation branding. Most of the previous studies considered two dimensions of social support in s-commerce context, which are: informational support and emotional support [53], [82]. These two dimensions have a positive influence on system reuse in the s-commerce environment [31], [64]. 


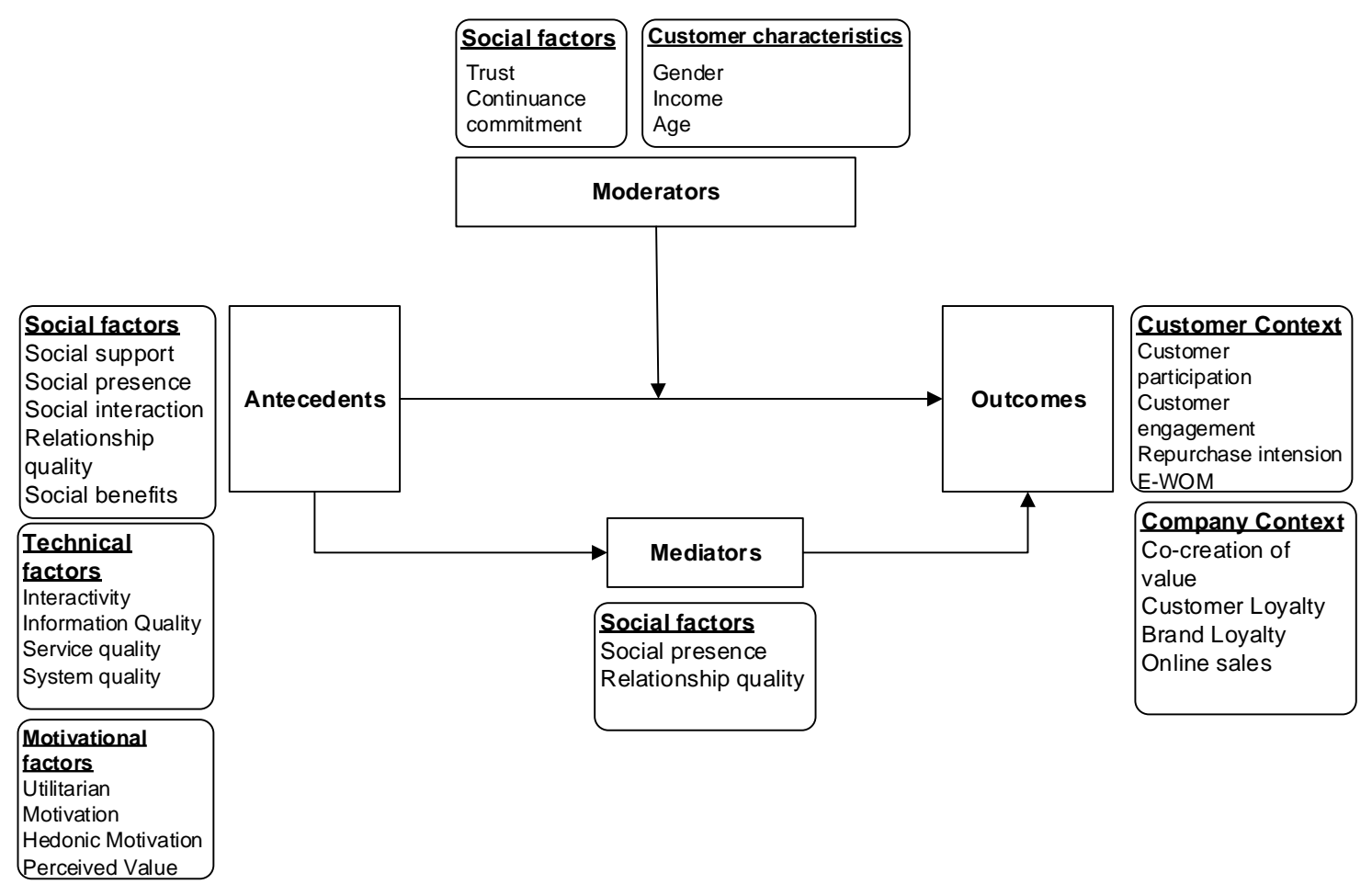

Figure 5: Research framework of factors influence customer engagement in s-commerce

Social presence was used as an antecedent in various CEB studies [21], [72], [74]. These have all explained social presence as the extent to which customers were able to establish a personal, warm and sociable interaction among each other in the s-commerce environment [96]. Other studies examined the mediation role of social presence in influencing online customer behavior to participate in s-commerce activities [33], [102].

As a number of studies have highlighted, social interaction is an important value that derives from the adoption and usage of new media [16], [34] S-commerce platforms, such as brand fan pages, provide opportunities for social interaction that can derive value [20], [70]. We noticed that a number of studies examined the impact of social interaction value on, namely: CE and the usage intensity in several contexts, such as Facebook and brand fan pages [20], [41], [47], online games [16], s-commerce [49], and mobile user engagement [49]. All of these studies focused on either interaction with other customers or interaction between customers and the brand or company.

Relationship quality refers to "the intensity and tightness of a relationship, which plays an important role in influencing customer loyalty" [66]. Prior research has utilised relationship quality as a lens through which to understand customers' interactions with brands [35], [52], [68]. Through the literature review, we identified three main components that help to construct relationship quality, namely: trust, relationship commitment, and relationship satisfaction [57], [91]. Trust refers to the belief that the service provider is honest and benevolent. Commitment defines a customer's desire to continue a relationship with a retailer [52]. Finally, satisfaction is defined as being the emotional state that represents the overall evaluation of interactive experience with the service provider [1], [25]. In the s-commerce context, CEB needs the establishment of trust, commitment and satisfaction in a buyer-seller relationship [68]. Relationship quality presents positive influence on CEB [25], [90].

In social network sites (SNSs), users are motivated to involve, promote and share information in the online brand community when they expect some benefits in return [104]. Social benefits refer to the benefits derived from the social relationships that develop over time among users [60]. Verhagen et al. [81] identified two typical social benefits obtained from the virtual customer environment. First, a customer can achieve a social identity within the community, which relates to the way in which a person thinks about him/herself [9]. Second, establishing social ties among customers allows them to interact with each other in solving problems, making sense or being involved in product/brand discussions. Several studies have examined social benefit as an antecedent for CEB [47], [68], [81], [104] customer feedback [39], and value co-creation [93].

\subsubsection{Technological Factors}

Interactivity is defined as the degree to which a communication technology allows the design of an environment where individuals can exchange messages and communicate with each other [4]. S-commerce, as a dynamic environment, allows customers to create content, share shopping experiences with others and post shopping messages [102]. Interactivity is considered to be a key engagement factor in the new e-commerce era. S-commerce with high perceived interactivity provides a suitable platform for self-presentation, content generation and exchange 
of social support [32], [102]. We noticed that numerous studies investigated the influence of interactivity in the scommerce context, including e-WOM [17], s-commerce sites [33], [102], and virtual environments such as virtual goods [81].

Information quality is one of the important factors introduced in the IS success model by DeLone \& McLean [22] for the success of information systems, specifically e-commerce systems. In the s-commerce context, information quality is defined as the degree to which customers are provided with information of excellent quality regarding their needs [46]. The more valuable detailed and accurate information provided the greater likelihood that the customer will retain and engage [57]. In [90], the author highlights that the quality of conveying messages in s-commerce websites by customers is influenced by the usage intention in Facebook fan pages. In [76], the authors have empirically showed the positive impact of information quality on satisfaction and intention to reuse e-commerce websites.

Service quality refers to the degree to which a user evaluates supports and services delivered by the service provider via the Website [52],[55]. Because s-commerce involves the use of a social networking site for commercial activities, design factors of social networking sites are expected to have significant influence on their users' social sharing and social shopping behavior. This subsequently, has a positive effect on the continuing use of s-commerce. Through our review, several studies have shown that service quality is a key factor for, customer trust [62], customer satisfaction [3], [10], [76], [94] continuance of use; and online engagement [21], [52], [55].

System quality is another technological factor that influences CEB in s-commerce. In [1], system quality has been defined in s-commerce context as the customer's evaluation of the degree of which the technical components of scommerce websites offer the quality of products and services required by customers. Moreover, there are other aspects that need to be considered as system quality. According to Delone and McLean [22], system quality depends on several factors, such as usability, adaptability, and response time of the system. In [46], the author suggests that accessibility and usability are important elements of s-commerce quality, which capture interface aspects of s-commerce design. For instance, customers expect to have e-commerce functions that are available all the time. In addition, they desire speedy log-on, access, search, and webpage download qualities. In addition, system quality in s-commerce is determined by system functions and services of both social network sites and ecommerce sites [52]. It is predicted that good system quality will make users feel that the site is a useful platform for social interaction and it may encourage them to keep using the site [37], [52], [89].

\subsubsection{Motivational Factors}

According to Anderson et al. [3], CEB in s-commerce environments requires a deep understanding of what motivates individuals to shop. The online shopping values represent a strong determinant of a customer's motivation. In [46], the authors have highlighted that recent studies focus on hedonic and utilitarian as two dimensions of web consumptions. In web consumption, the hedonic and utilitarian motivations are determined by the degree of utility provided and/or the enjoyment provided to users [69]. Both utilitarian and hedonic aspects have been analysed to explore the characteristics of online shopping behavior [97]. Utilitarian behavior is defined as goal-oriented and rational, concerned with effectiveness and instrumental value [69]. Customers with utilitarian motivation seek to achieve certain goals through online communities such as finding information about products or services before they make any purchasing decisión [48].

On the other hand, hedonic motivation focuses on a customer's emotional needs, which takes into account nonfunctional behaviors' sensuality, enjoyment and happiness. In [3], the authors refer to hedonic motivations as a customer's enjoyment of the shopping experience itself. Studies have empirically shown that when the user believes that a system satisfies his/her pleasure and fun needs, this will have a positive effect on users' attitudes. Moreover, this attitude could be directed towards using an information system, website, or repurchasing of products and services [98]. Customer interaction in any s-commerce environment such as Facebook could be highly interesting and pleasurable sources [12], [68]. Thus, the enjoyment derived from the interaction with fan pages leads to engagement in these pages [17], [20]. However, hedonic and utilitarian value were found to be the key drivers for scommerce engagement [60]. In [46], the authors have deduced that both hedonic and utilitarian motivations have a positive effect on a customer's repurchase intention.

\subsubsection{Moderators}

Moderator is a research variable that affects the direction and/or even the strength of the relationship between an independent variable and dependent variable [7], [29], [61]. The moderators used in CE research can be classified as social factors and customer/user characteristics. For example, [39] used continuous commitment to moderators as the relationship between social benefits and customer feedback. Results showed that continuance commitment of customers by communication using WOM moderates the relationship between social benefits and customer feedback. This occurs specifically when customer commitment is high, experiencing social benefits from company staff having a strong positive effect on customer feedback. [9] used trust in Facebook as a moderator by which to study the effect of interaction with friends on CEbehavior.

User characteristics refer to the demographic variable, cultural differences and user personality [100]. Previous studies have analyzed how a customer's characteristics can affect the relationship between antecedents and 
outcome behavior. In [25], [62], [101] the authors have used demographic variables including gender, age and income. In [101], the authors have studied the impact of prior experience in co-innovation as a moderator affecting the relationship between motivational factors and customers' attitudes towards engagement in online co-innovation communities.

\subsubsection{Outcomes}

The SLR results show several constructs were studied as an outcome the CE research. These outcomes were classified into two main dimensions: customer context and company context. The constructs that examined customer context comprises CE intention/behavior; customer participation; repurchase intention; and electronic word of mouth (e-WOM). In particular, customer engagement and participation were studied extensively. In [54], the authors examined the drivers of CE intention in virtual customer environments using UGT. In [20], UGT used to investigate the gratification factors that influence usage intensity and CEB in the social media environment. In [103], the authors have studied the impact of value co-creation experience and technological environment on customers' intentions towards future participation. Repurchase intention and e-WOM were studied together as consequences of CE. In [46], the autohrs have studied repurchase intention as an outcome construct that is affected by customer satisfaction and shopping values. On the other hand, other studies considered repurchase intention [86], and e-WOM [41], [86], [91], [98] as a consequence of CE in s-commerce activities.

With regard to company context, we highlighted that customer loyalty, online sales, co-creation and brand loyalty are the most investigated variables in the prior studies. In [40], the authors have examined the effect of brand image and brand love on CE in the fashion apparel context, which leads to customer loyalty as a direct outcome. In [41], the authors have investigated the effect of fan brand pages on the customer-brand relationship and showed that fan page usage intensity and fan page engagement have a positive impact on customer brand loyalty. In [60], the authors have investigated in-depth the customer benefits perceived from virtual customer environments that influence customer participation in value co-creation. In [93], the authors have studied the effect of s-commerce constructs and social support on the development of a brand through co-creation in branding.

\section{Discussion and Implications}

The purpose of this study is to conduct a systematic literature review on customer engagement in s-commerce. The growth of s-commerce usage shows the influence on the engaging customers in this new phenomenon, while research on this issue is scattered and limited, we derive insights through an extensive review of theories, model and factors that influence customer engagementin s-commerce. We focused on empirical research studies that examine the factors affecting CEB in the s-commerce context. A total of 108 studies were identified through our systematic review from prominent academic data bases. Through the collected studies, we noticed increasing publication trends in the emerging areas of s-commerce and CEB. More importantly, we propose a reserach framework to expose the antecedents, moderators and outcomes of CE. Moreover, based on our analysis, we categorised the antecedents into three dimensions: social, technological and motivational. This effort will be valuable for both academics and practitioners and will contribute to the understanding of this domain. We also anticipate that it will unleash the potential for more research in the future.

This study is one of the first to thoroughly review the factors that affect CEB in s-commerce. Therefore, the findings of the study carry several important implications for both researchers and practitioners who are interested in customer behaviour in s-commerce. First, we provide a systematic review of current studies on CE and uncover the theories, models, factors, and clarify the customer engagement concept. This can advance the knowledge on what stimulate customers to engage in s-commerce.

Second, this study is one of the earliest studies that provides theoretical dimensions for CEB in s-commerce (Social, technological, motivation, and behavioural). Furthermore, the results show that social factors such as (social support and social interactions, and social benefits) play an important role in engaging customers in s-commerce activities. Several research studies have emphasised the social aspect of s-commerce as the main antecedent for customers to engage in activities that go beyond purchase. This suggests a further empirical research on the social factors in order to have more insights on the social aspect in s-commerce. Similarly, the quality of s-commerce websites and accuracy of information provided have potential impact on CEB. More practically, the influence of technological factors (interactivity, information quality and service quality) enrich the communication between customers and develop participant conversation [104].

Third, the identified antecedents and moderators in our framework are likely to help the companies to understand better what stimulates customers to participate in the company's websites. Thus, many companies and online businesses consider utilising the factors to empower the s-commerce websites. However, this study will enhance scommerce website managers' understanding of better features that can be used by customers during their surfing scommerce websites. For example, trust plays a key role as a moderator factor, and mangers who are aware of the influential role of trust and trust performance should take necessary steps to ensure that e-commerce is trusted within their s-commerce company. Overall, the results of this study will provide a long-term impact to IS and marketing research by providing a theoretical basis for developing empirical research on CE, and it paves the way for addressing the CE in the context of s-commerce. 


\section{Conclusion}

This study provides a systematic review of customer engagament behavior in s-commerce. The study derives insights based on the discussion of customer engagement conceptualization, theroies, model and factors of selected primary studies. By reviewing the current studies in customer engagament and s-commerce, and provide a mind map on the different types of customer engagament, we consider this effort would be valuable for e-commerce reserach and parctitioners. As s-commerce is still evolving and rapidly increasing, this review is acts as a potential foundation for reserachers to help indentifying new reserach opprtunities.

\section{References}

[1] H. H. Alshibly, A free simulation experiment to examine the effects of social commerce website quality and customer psychological empowerment on customers satisfaction, Journal of Business Studies Quarterly, vol. 5, no. 4, pp. 21-40, 2014.

[2] N. Amblee, B. Tung Harnessing the influence of social proof in online shopping, International Journal of Electronic Commerce, vol. 4415, no. November, pp. 91-114, 2011.

[3] K. C. Anderson, D. K. Knight, S. Pookulangara, and B. Josiam, Influence of hedonic and utilitarian motivations on retailer loyalty and purchase intention: A facebook perspective, Journal of Retailing and Consumer Services, vol. 21, pp. 773-779, 2014.

[4] A. Animesh and A. Pinsonneault, An odyssey into virtual worlds: exploring the impacts of technological and spatial environments on intention to purchase virtual products, MIS Quarterly, vol. 35, no. 3, p. 789, 2011.

[5] Y. Bai, Z. Yao and Y.-F. Dou, Effect of social commerce factors on user purchase behavior: An empirical investigation from renren.com, International Journal of Information Management, vol. 35, no. 5, pp. 538-550, 2015.

[6] W. Bandara, S. Miskon and E. Fielt, A systematic, tool-supported method for conducting literature reviews in information systems, in Proceedings of 19th Eroupean conference on Information Systems, Helsinki, 2011, pp. 221-233.

[7] R. M. Baron and D. A. Kenny, The moderator-mediator variable distinction in social psychological research: conceptual, strategic, and statistical considerations, Journal of Personality and Social Psychology, vol. 51, no. 6, pp. 1173-1182, 1986.

[8] T. H. a. Bijmolt et al., Analytics for customer engagement, Journal of Service Research, vol. 13, no. 3, pp. 341356, 2010.

[9] S. Bitter, S. G. Kräuter and R. J. Breitenecker, Customer engagement behaviour in online social networks - the Facebook perspective, International Journal of Networking and Virtual Organisations, vol. 14, no. 1/2, p. 197, 2014.

[10] A. Bhattacherjee, An empirical analysis of the antecedents of electronic commerce service continuance, Decision Support Systems, vol. 32, no. 2, pp. 201-214, 2001.

[11] J. L.-H. Bowden, The process of customer engagement: A conceptual framework, The Journal of Marketing Theory and Practice, vol. 17, no. 1, pp. 63-74, 2008.

[12] L. Blasco-Arcas, B. Hernandez-Ortega and J. Jimenez-Martinez, Adopting television as a new channel for ecommerce. The influence of interactive technologies on consumer behavior, Electronic Commerce Research, vol. 13, pp. 457-475, 2013.

[13] R. J. Brodie, L. D. Hollebeek, B. Juric, and A. Ilic, Customer engagement: Conceptual domain, fundamental propositions, and implications for research, Journal of Service Research, vol. 14, pp. 252-271, 2011.

[14] K. K. Celuch, N. M. Robinson and A. M. Walsh, A framework for encouraging retail customer feedback, Journal of Services Marketing, vol. 29, no. 4, pp. 280-292, 2015.

[15] T. K. H. Chan, M. K. O. Lee and Z. W. Y. Lee, Antecedents and consequences of customer engagement in online brand communities, Journal of Marketing Analytics, vol. 2, no. 2, pp. 81-97, 2014.

[16] C. M. K. Cheung, X.-L. Shen, Z. W. Y. Lee, and T. K. H. Chan, Promoting sales of online games through customer engagement, Electronic Commerce Research and Applications, vol. 14, no. 4, pp. 241-250, 2015.

[17] S.-C. Chu and Y. Kim, Determinants of consumer engagement in electronic word-of-mouth (eWOM) in social networking sites, International Journal of Advertising, vol. 30, no. 1, p. 47, 2011.

[18] R. E. Crossler, Intention to engage in social commerce: Uses and gratifications approach, in Proceedings the Twentieth Americas Conference on Information Systems, Savannah, 2014, pp. 1-12.

[19] R. G. Curty and P. Zhang, Social commerce: Looking back and forward, in Proceedings of the American Society for Information Science and Technology, vol. 48, no. 1, pp. 1-10, 2011.

[20] N. De Vries and J. Carlson, Examining the drivers and brand performance implications of customer engagement with brands in the social media environment, Journal of Brand Management, vol. 21, no. 6, pp. 1-21, 2014.

[21] M. J. De Oliveira, M. K. Z. Huertas and Z. Lin, Factors driving young users' engagement with Facebook: Evidence from Brazil, Computers in Human Behavior, vol. 54, pp. 54-61, 2016.

[22] W. H. Delone and E. R. Mclean, The Delone and McLean model of information systems success: A ten-year update, Journal of Management Information Systems, vol. 19, no. 4, pp. 9-30, 2003.

[23] W. H. Delone and E. R. Mclean, Measuring e-commerce success : Applying the DeLone \& McLean information systems success model, International Journal of Electronic Commerce, vol. 9, no. 1, pp. 37-41, 2004. 
[24] E. R. DeLone, W. H. and McLean, Information systems success: The quest for the dependent variable, Information Systems Research, vol. 3, no. 1, pp. 60-95, 1992.

[25] J.-R. Fu, P.-H. Ju and C.-W. Hsu, Understanding why consumers engage in electronic word-of-mouth communication: Perspectives from theory of planned behavior and justice theory, Electronic Commerce Research and Applications, vol. 14, no. 6, pp. 616-630, 2015.

[26] B. H. Gottlieb and A. E. Bergen, Social support concepts and measures, Journal of Psychosomatic Research, vol. 69 , no. 5, pp. 511-520, 2010.

[27] A. Gruzd, B. Wellman and Y. Takhteyev, Imagining twitter as an imagined community, American Behavioral Scientist, vol. 55, no. 10, pp. 1294-1318, 2011

[28] L. Guo-xin and Y. Xue, Exploring social commerce adoption in China: A uses and gratification perspective, in Proceedgins International Conference on Management Science \& Engineering, Helsinki, 2014, pp. 546-554.

[29] J. F. Hair, J. G. T. M. Hult, C. M. Ringle, and M. Sarstedt, A Primer on Partial Least Squares Structural Equation Modeling (PLS-SEM). Sage Publications, California, 2014.

[30] N. Hajli, A research framework for social commerce adoption, Information Management \& Computer Security, vol. 21, pp. 144-154, 2013.

[31] N. Hajli and J. Sims, Social commerce: The transfer of power from sellers to buyers, Technological Forecasting and Social Change, vol. 94, pp. 350-358, 2015.

[32] N. Hajli, The role of social support on relationship quality and social commerce, Technological Forecasting and Social Change, vol. 87, pp. 17-27, 2014.

[33] N. Hajli, M. Shanmugam, P. Powell, and P. E. D. Love, A study on the continuance participation in on-line communities with social commerce perspective, Technological Forecasting and Social Change, vol. 96, pp. 232241,2015

[34] T. Hennig-Thurau et al., The impact of new media on customer relationships, Journal of Service Research, vol. 13, pp. 311-330, 2010.

[35] T. Hennig-Thurau, K. P. Gwinner and D. D. Gremler, Understanding relationship marketing outcomes: An integration of relational benefits and relationship quality, Journal of Service Research, vol. 4, no. 3, pp. 230-247, 2002.

[36] L. D. Hollebeek, Demystifying customer brand engagement: Exploring the loyalty nexus, Journal of Marketing Management, vol. 27, no. 7-8, pp. 785-807, 2011.

[37] Z. Huang and M. Benyoucef, From e-commerce to social commerce: A close look at design features, Electronic Commerce Research and Applications, vol. 12, no. 4, pp. 246-259, 2013.

[38] K. Hur, T. T. Kim, O. M. Karatepe, and G. Lee, An exploration of the factors influencing social media continuance usage and information sharing intentions among Korean travellers, Tourism Management, vol. 63, pp. $170-178,2017$

[39] M. I. Hwang and R. G. Thorn, The effect of user engagement on system success: A meta-analytical integration of research findings, Information \& Management, vol. 35, no. 4, pp. 229-236, 1999.

[40] J. U. Islam and Z. Rahman, Examining the effects of brand love and brand image on customer engagement: An empirical study of fashion apparel brands, Journal of Global Fashion Marketing, vol. 7, no. 1, pp. 45-59, 2016.

[41] B. Jahn and W. Kunz, How to transform consumers into fans of your brand, Journal of Service Management, vol. 23, no. 3, pp. 344-361, 2012.

[42] H. Jang, I. Ko and J. Kim, The effect of group-buy social commerce and coupon on satisfaction and continuance intention: Focusing on the expectation confirmation model, in Proceedings the Annual Hawaii International Conference on System Sciences, Hawaii, 2013, pp. 2938-2948.

[43] E. Katz, J. G. Blumler and M. Gurevitch, Uses and gratifications research, The public Opinion Quarterly, vol. 14, no. 3, pp. 419-442, 1973.

[44] S. Kim and H. Park, Effects of various characteristics of social commerce (s-commerce) on consumers' trust and trust performance, International Journal of Information Management, vol. 33, no. 2, pp. 318-332, 2012.

[45] D. Kim, Under what conditions will social commerce business models survive?, Electronic Commerce Research and Applications, vol. 12, no. 2, pp. 69-77, 2013

[46] C. Kim, R. D. Galliers, N. Shin, J.-H. Ryoo, and J. Kim, Factors influencing internet shopping value and customer repurchase intention, Electronic Commerce Research and Applications, vol. 11, no. 4, pp. 374-387, 2012.

[47] J. B. Kim, The mediating role of presence on consumer intention to participate in a social commerce site, Journal of Internet Commerce, vol. 14, no. 4, pp. 425-454, 2015.

[48] S.-B. Kim, K.-A. Sun and D.-Y. Kim, The influence of consumer value-based factors on attitude-behavioral intention in social commerce: The differences between high- and low-technology experience groups, Journal of Travel and Tourism Marketing, vol. 30, no. 1, pp. 108-125, 2013.

[49] Y. H. Kim, D. J. Kim and K. Wachter, A study of mobile user engagement (MoEN): Engagement motivations, perceived value, satisfaction, and continued engagement intention, Decision Support Systems, vol. 56, pp. 361$370,2013$.

[50] V. Kumar, L. Aksoy, B. Donkers, R. Venkatesan, T. Wiesel, and S. Tillmanns, Undervalued or overvalued customers: Capturing total customer engagement value, Journal of Service Research, vol. 13, pp. 297-310, 2010.

[51] B. Lakey and S. Cohen, Social support theory and measurement, in Social Support Measurement and Intervention, (S. Cohen, L. Underwood and B. Gottie, Eds.). New York, USA: Oxfrod University press, 2000, pp. 29-52. 
[52] T.-P. Liang, Y.-T. Ho, Y.-W. Li, and E. Turban, What drives social commerce: The role of social support and relationship quality, International Journal of Electronic Commerce, vol. 16, no. 2, pp. 69-90, 2011

[53] T.-P. Liang and E. Turban, Introduction to the special issue social commerce: A research framework for social commerce, International Journal of Electronic Commerce, vol. 16, no. 2, pp. 5-14, 2011.

[54] H. Li, Y. Liu, X. Xu, J. Heikkilä, and H. Van Der Heijden, Modeling hedonic is continuance through the uses and gratifications theory: An empirical study in online games, Computers in Human Behavior, vol. 48, pp. 261-272, 2015.

[55] C.-J. Liang and H.-J. Chen, A study of the impacts of website quality on customer relationship performance, Total Quality Management \& Business Excellence, vol. 20, no. 9, pp. 971-988, 2009.

[56] W. M. Lim and D. H. Ting, E-shopping: An analysis of the uses and gratifications theory, Modern Applied Science, vol. 6, no. 5, pp. 48-63, 2012.

[57] W. M. Lim, Untangling the relationships between consumer characteristics, shopping values, and behavioral intention in online group buying, Journal of Strategic Marketing, vol. 4488, no. November, pp. 1-20, 2016.

[58] P. Marsden and C. Paul, The Social Commerce Handbook: 20 Secrets for Turning SocialMedia Into Social Sales. New York: McGraw-Hill, 2012.

[59] W. Nadeem, D. Andreini, J. Salo, and T. Laukkanen, Engaging consumers online through websites and social media: A gender study of Italian generation y clothing consumers, International Journal of Information Management, vol. 35, no. 4, pp. 432-442, 2015.

[60] S. Nambisan and R. a. Baron, Virtual customer environments: Testing a model of voluntary participation in value co-creation activities, Journal of Product Innovation Management, vol. 26, no. 518, pp. 388-406, 2009.

[61] E. W. T. Ngai, S. S. C. Tao and K. K. L. Moon, Social media research: Theories, constructs, and conceptual frameworks, International Journal of Information Management, vol. 35, no. 1, pp. 33-44, 2015.

[62] P. Patterson, T. Yu and K. De Ruyter, Understanding customer engagement in services, in Proceedings of Australia-New Zealand Marketing Academy Conference, New Zealand, 2006, pp. 69-75.

[63] E. Pöyry, P. Parvinen and T. Malmivaara, Can we get from liking to buying? Behavioral differences in hedonic and utilitarian Facebook usage, Electronic Commerce Research and Applications, vol. 12, pp. 224-235, 2013.

[64] C. M. Ridings and D. Gefen, Virtual community attraction: Why people hang out online, Journal of ComputerMediated Communication, vol. 10, no. 1, 2004.

[65] A. Rohm, V. D. Kaltcheva and G. R. Milne, A mixed-method approach to examining brand-consumer interactions driven by social media, Journal of Research in Interactive Marketing, vol. 7, pp. 295-311, 2013.

[66] J. Romero, Exploring customer engagement behavior: Construct proposal and its antecedents, in Proceedings of 2nd International Symposium on Partial Least Squares Path Modeling, Seville, 2015, pp. 1-12.

[67] A. M. Rubin, An examination of television viewing motives, Journal of Communication, vol. 8, no. 3, pp. 141-165, 1994.

[68] C. M. Sashi, Customer engagement, buyer-seller relationships, and social media, Management Decision, vol. 50, no. 2, pp. 253-272, 2012.

[69] C. See-Pui Ng, Intention to purchase on social commerce websites across cultures: A cross-regional study, Information and Management, vol. 50, no. 8, pp. 609-620, 2013.

[70] M. Shanmugam, S. Sun, A. Amidi, F. Khani, and F. Khani, The applications of social commerce constructs, International Journal of Information Management, vol. 36, no. 3, pp. 425-432, 2016.

[71] M. Shanmugam and Y. Y. Jusoh, Social commerce from the Information Systems perspective: A systematic literature review, in Proceedings of International Conference on Computer and Information Sciences, Kuala Lumpur, 2014, pp. 1-6.

[72] S. Sharma and R. E. Crossler, Disclosing too much? Situational factors affecting information disclosure in social commerce environment, Electronic Commerce Research and Applications, vol. 13, no. 5, pp. 305-319, 2014.

[73] C. Sheldon and U. Lynn, Social Support Measurement and Intervention: A Guide for Health and Social Scientists. New York, USA: Oxfrod University press, 2000.

[74] J. Shen, Social comparison, social presence and enjoyment in the acceptance of social shopping websites, Journal of Electronic Commerce Research, vol. 13, pp. 198-213, 2012.

[75] D.-H. Shin, User experience in social commerce: In friends we trust, Behaviour \& Information Technology, vol. 32 , no. 1, pp. 52-67, 2013.

[76] J. Song, J. Baker, S. Lee, and J. C. Wetherbe, Examining online consumers' behavior: A service-oriented view, International Journal of Information Management, vol. 32, no. 3, pp. 221-231, 2012.

[77] L. Sturiale and A. Scuderi, Evaluation of social media actions for the agrifood system, Procedia Technology, vol. 8, pp. 200-208, 2013.

[78] J. Van Doorn et al., Customer engagement behavior: Theoretical foundations and research directions, Journal of Service Research, vol. 13, pp. 253-266, 2010.

[79] S. L. Vargo and R. F. Lusch, Evolving to a new dominant logic for marketing, Journal of Marketing, vol. 68, no. 1, pp. 1-17, 2004

[80] S. L. Vargo and R. F. Lusch, Service-dominant logic: Continuing the evolution, Journal of the Academy of Marketing Science, vol. 36, no. 1, pp. 1-10, 2008.

[81] T. Verhagen, F. Feldberg, B. Van Den Hooff, S. Meents, and J. Merikivi, Understanding users' motivations to engage in virtual worlds: A multipurpose model and empirical testing, Computers in Human Behavior, vol. 28, no. 2, pp. 484-495, 2012.

[82] T. Verhagen, E. Swen, F. Feldberg, and J. Merikivi, Benefitting from virtual customer environments: An empirical study of customer engagement, Computers in Human Behavior, vol. 48, pp. 340-357, 2015. 
[83] P. C. Verhoef, W. J. Reinartz and M. Krafft, Customer engagement as a new perspective in customer management, Journal of Service Research, vol. 13, no. 3, pp. 247-252, 2010.

[84] K. Verleye, P. Gemmel and D. Rangarajan, Managing engagement behaviors in a network of customers and stakeholders: Evidence from the nursing home sector, Journal of Service Research, vol. 17, no. 1, pp. 68-84, 2014.

[85] S. D. Vivek, S. E. Beatty, V. Dalela, and R. M. Morgan, A generalized multidimensional scale for measuring customer engagement, Journal of Marketing Theory and Practice, vol. 22, no. 4, pp. 37-41, 2014.

[86] S. D. Vivek, S. E. Beatty, V. Dalela, and R. M. Morgan, A generalized scale for measuring customer engagement, Journal of Marketing Theory and Practice, no. 2015, pp. 37-41, 2014.

[87] S. D. Vivek, S. E. Beatty and R. M. Morgan, Customer engagement: Exploring customer relationships beyond purchase, The Journal of Marketing Theory and Practice, vol. 20, no. 2, pp. 122-146, 2012.

[88] C. Wagner and A. Majchrzak, Enabling customer-centricity using wikis and the wiki way, Journal of Management Information Systems, vol. 23, no. 3, pp. 17-43, 2007.

[89] Y. S. Wang, Assessing e-commerce systems success: A respecification and validation of the DeLone and McLean model of IS success, Information Systems Journal, vol. 18, no. 5, pp. 529-557, 2008.

[90] S.-M. Wang, Exploring the factors influencing the usage intention of Facebook fan page - A preliminary study, in Proceedings of 19th Americas Conference on Information Systems, Chicago, 2013, pp. 1595-1600.

[91] C. Wang and P. Zhang, The Evolution of Social Commerce: The people, management, technology, and information dimensions, Communications of the Association for Information Systems, vol. 31, pp. 105-127, 2012.

[92] Q. Wang, J. Xu and J. Liu, Group purchase: A win-win combination of social networking services with ecommerce typical representative-Nuomi.com, in Proceedings of 2nd International Conference on Information Science and Engineering, Hangzhou, 2010, pp. 2111-2114.

[93] Y. Wang, C. Management, J. Raymond, and N. Hajli, Co-creation in branding through social commerce: The role of social support, relationship quality and privacy concerns, in Proceedings of Twentieth Americas Conference on Information Systems, Savannah, 2014, pp. 1-16.

[94] W.-T. Wang, Y.-S. Wang and E.-R. Liu, The stickiness intention of group-buying websites: The integration of the commitment-trust theory and e-commerce success model, Information \& Management, vol. 53, no. 5, pp. 625642, 2016

[95] J. Webster and R. Watson, Analyzing the past to prepare for the future: Writing a literature review, MIS Quarterly, vol. 26, no. 2, pp. 13-23, 2002.

[96] L. Xiang, X. Zheng, H. Zhang, and X. Hu, What Drive Social commerce: The role of Parasocial intreaction, in Proceedings of the 19th Pacific Asia Conference on Information Systems, Chengdu, 2014, pp. 86-100.

[97] C. Xu, S. Ryan, V. Prybutok and C. Wen, It is not for fun: An examination of social network site usage, Information and Management, vol. 49, no. 5, pp. 210-217, 2012.

[98] K. Yang, X. Li, H. Kim and Y. H. Kim, Social shopping website quality attributes increasing consumer participation, positive eWOM, and co-shopping: The reciprocating role of participation, Journal of Retailing and Consumer Services, vol. 24, pp. 1-9, 2015.

[99] K. Z. Zhang and M. Benyoucef, Consumer behavior in social commerce: A literature review, Decision Support Systems, vol. 86, pp. 95-108, 2016.

[100]K. Z. K. Zhang, M. Benyoucef and S. J. Zhao, Consumer participation and gender differences on companies' microblogs: A brand attachment process perspective, Computers in Human Behavior, vol. 44, pp. 357-368, 2015.

[101]T. Zhang, J. Kandampully and A. Bilgihan, Motivations for customer engagement in online co-innovation communities (OCCs): A conceptual framework, Journal of Hospitality and Tourism Technology, vol. 26, no. 5, pp. 777-806, 2015.

[102] H. Zhang, Y. Lu, S. Gupta and L. Zhao, What motivates customers to participate in social commerce? The impact of technological environments and virtual customer experiences, Information Management, vol. 51, pp. 1017-1030, 2014.

[103] H. Zhang, Y. Lu, B. Wang and S. Wu, The impacts of technological environments and co-creation experiences on customer participation, Information \& Management, vol. 52, no. 4, pp. 468-482, 2015.

[104]X. Zheng, C. M. K., K. O. C. Matthew, and L. L. Liang, Building brand loyalty through user engagement in online brand communities, Information Technology \& People, vol. 28, no. 1, pp. 90-106, 2015.

[105] L. Zhou, P. Zhang and H. D. Zimmermann, Social commerce research: An integrated view, Electronic Commerce Research and Applications, vol. 12, no. 2, pp. 61-68, 2013. 